\title{
Article \\ Pd Catalysts Supported on Bamboo-Like Nitrogen-Doped Carbon Nanotubes for Hydrogen Production
}

\author{
Arina N. Suboch and Olga Y. Podyacheva *(D) \\ Boreskov Institute of Catalysis SB RAS, 630090 Novosibirsk, Russia; arina@catalysis.ru \\ * Correspondence: pod@catalysis.ru
}

\begin{abstract}
Bamboo-like nitrogen-doped carbon nanotubes (N-CNTs) were used to synthesize supported palladium catalysts (0.2-2 wt.\%) for hydrogen production via gas phase formic acid decomposition. The beneficial role of nitrogen centers of N-CNTs in the formation of active isolated palladium ions and dispersed palladium nanoparticles was demonstrated. It was shown that although the surface layers of N-CNTs are enriched with graphitic nitrogen, palladium first interacts with accessible pyridinic centers of N-CNTs to form stable isolated palladium ions. The activity of $\mathrm{Pd} / \mathrm{N}-\mathrm{CNTs}$ catalysts is determined by the ionic capacity of N-CNTs and dispersion of metallic nanoparticles stabilized on the nitrogen centers. The maximum activity was observed for the $0.2 \%$ $\mathrm{Pd} / \mathrm{N}-\mathrm{CNTs}$ catalyst consisting of isolated palladium ions. A ten-fold increase in the concentration of supported palladium increased the contribution of metallic nanoparticles with a mean size of $1.3 \mathrm{~nm}$ and decreased the reaction rate by only a factor of 1.4 .
\end{abstract}

Keywords: hydrogen; formic acid; palladium; nitrogen; carbon nanotubes

Citation: Suboch, A.N.; Podyacheva, O.Y. Pd Catalysts Supported on Bamboo-Like Nitrogen-Doped Carbon Nanotubes for Hydrogen Production. Energies 2021, 14, 1501. https://doi.org/10.3390/en14051501

Academic Editor: Javier Fermoso

Received: 18 February 2021

Accepted: 3 March 2021

Published: 9 March 2021

Publisher's Note: MDPI stays neutral with regard to jurisdictional claims in published maps and institutional affiliations.

Copyright: (c) 2021 by the authors. Licensee MDPI, Basel, Switzerland. This article is an open access article distributed under the terms and conditions of the Creative Commons Attribution (CC BY) license (https:/ / creativecommons.org/licenses/by/ $4.0 /)$.

\section{Introduction}

Rational use of fossil fuel resources is a necessary condition for the long-term stable development of society. In this context, the development of efficient processes for energy production from renewable sources is a topical problem that can be solved using various fundamental studies, particularly in the field of material science. Hydrogen production from formic acid (FA) is a way to involve renewable biomass sources into the energy cycle [1,2]. The FA decomposition reaction proceeds on mono-, bi- and trimetallic catalysts deposited on oxide or carbon supports [3,4]. Activity and selectivity of the catalysts towards hydrogen production are determined by the nature of their active component, its dispersion, and electronic state of metals. The application of nitrogen-doped carbon nanomaterials (N-CNMs) as the catalyst supports makes it possible to perform the tailored synthesis of metal supported catalysts with desired properties [5].

It is known that nitrogen in N-CNMs having different structures occupies standard positions: pyridinic $\left(\mathrm{N}_{\mathrm{Py}}\right)$, pyrrolic $\left(\mathrm{N}_{\mathrm{Pyr}}\right)$, graphitic $\left(\mathrm{N}_{\mathrm{Q}}\right)$, and oxidized $\left(\mathrm{N}_{\mathrm{Ox}}\right)$. According to data in the literature, supported metals can stabilize on different nitrogen centers. For example, Pt stabilization on $\mathrm{N}_{\mathrm{Q}}$ centers of nitrogen-doped carbon nanotubes (N-CNTs) leads to the formation of electron-rich Pt nanoparticles, which are active towards the hydrogenation of nitroarenes [6] and aerobic oxidation of glycerol [7]. Ombaka et al. [8] reported the formation of $\mathrm{Pd}^{2+}$ species on the $\mathrm{N}_{\text {Pyr }}$ centers of $\mathrm{N}-\mathrm{CNTs}$, which are active towards the hydrogenation of nitrobenzophenone [8]. However, a substantial body of data indicates the involvement of $\mathrm{N}_{\mathrm{Py}}$ centers in the stabilization of electron-deficient metals on the surface of various N-CNMs, which show the increased activity and selectivity in hydrogenation reactions or electrochemical reduction of oxygen [9-12]. The positive role of the electron-deficient metals deposited on ordered or disordered N-CNMs was also demonstrated for FA decomposition in a liquid or gaseous medium [4,13-16]. Additionally, for platinum deposited on nitrogen-doped carbon nanofibers (N-CNFs) and N-CNTs, it 
was shown that the catalytic properties of metal in this reaction are determined by its locally one-type interaction with $\mathrm{N}_{\mathrm{Py}}$ centers [16]. Among various metals that are active towards FA decomposition, platinum and palladium are the most active catalysts for this reaction [3,17]. It should be noted that the use of $\mathrm{N}-\mathrm{CNMs}$ as the supports opens new possibilities for enhancing the efficiency of catalysts via the stabilization of highly active and selective atomic metal species $[18,19]$. Among the wide variety of N-CNMs, bamboo-like N-CNTs are characterized by a unique combination of the graphene layer curvature and the availability of all nitrogen centers. At the same time, data on the use of these materials as a support for the catalysts of the FA decomposition reaction are quite scarce [18].

This paper is devoted to investigating the formation of the Pd catalyst on bamboo-like $\mathrm{N}-\mathrm{CNTs}$ for the gas phase formic acid decomposition reaction. A detailed investigation of the properties of N-CNTs, variation of palladium concentration, and application of various research methods allowed us to describe the interaction of palladium with the surface of N-CNTs. Different active palladium species were shown to form as isolated ions and metallic nanoparticles with a size of $1.3 \mathrm{~nm}$, the ratio of which were determined by the affinity of palladium for $\mathrm{N}_{\mathrm{Py}}$ centers and the palladium concentration in catalysts.

\section{Materials and Methods}

Nitrogen-doped and nitrogen-free carbon nanotubes (N-CNTs and CNTs) were synthesized by the standard CVD route [20]. An ethylene-ammonia mixture or ethylene were decomposed on the Fe-containing catalyst at $650-700^{\circ} \mathrm{C}$. The growth catalyst was removed by the boiling of N-CNTs and CNTs in $2 \mathrm{M}$ hydrochloric acid. Nevertheless, X-ray photoelectron spectroscopy (XPS) revealed the presence of iron in the washed samples with the content up to approximately 0.5 at.\%. Previously, we have demonstrated the low intrinsic activity of washed N-CNTs and CNTs in FA decomposition reactions compared to metal supported catalysts [16]. Palladium was deposited on carbons, which were pre-dried in $\mathrm{Ar}$ at $170^{\circ} \mathrm{C}$, by incipient wetness impregnation from a Pd acetate-acetone solution. The samples were dried in air at $105^{\circ} \mathrm{C}$ for $8 \mathrm{~h}$ and then reduced in an $\mathrm{H}_{2} / \mathrm{Ar}$ flow at $200{ }^{\circ} \mathrm{C}$ for $1 \mathrm{~h}$.

Nitrogen adsorption measurements were carried out at $77 \mathrm{~K}$ by the use of ASAP-2400. Prior to measurements, the samples were evacuated at $200{ }^{\circ} \mathrm{C}$ for $24 \mathrm{~h}$. Acetone capacity of the N-CNTs and CNTs was measured by the standard incipient wetness impregnation method. Acetone was added dropwise under stirring to the sample dried in $\mathrm{Ar}$ at $170{ }^{\circ} \mathrm{C}$ until the pores of the material were completely filled. The volume of the absorbed acetone $\left(\mathrm{cm}^{3} / \mathrm{g}\right)$ was determined by weighing. $\mathrm{CO}$ chemisorption on the catalysts was measured at room temperature by a pulse technique. Before the experiments, the catalysts were reduced in hydrogen flow at $200{ }^{\circ} \mathrm{C}$. X-ray diffraction patterns were recorded using an HZG-4 (Zeiss, Germany) diffractometer with monochromatic $\mathrm{CuK}_{\alpha}$ radiation. Electron microscopy investigation was performed using JEM-2200 FS (JEOL Ltd., Japan) and Titan 60-300 (FEI, Netherlands) electron microscopes. Raman spectroscopy with an excitation wavelength of $632.8 \mathrm{~nm}$ was performed using a HORIBA LabRAM HR800 (HORIBA Jobin Yvon Raman Division, France) Raman spectrometer. XPS study of N-CNTs was performed on an ES-300 (KRATOS Analytical, UK) photoelectron spectrometer with an AlK $\alpha$ source $(\mathrm{h} v=1486.6 \mathrm{eV})$. The distribution of nitrogen in N-CNTs was studied by synchrotronbased photoelectron spectroscopy at 500 and $800 \mathrm{eV}$ photon energy [21]. Pd catalysts were examined using a VG ESCALAB HP (ThermoScientific, UK) instrument with an AlK $\alpha$ source $(\mathrm{h} v=1486.6 \mathrm{eV})$. In situ reduction of the catalysts under $1000 \mathrm{~Pa} \mathrm{H}_{2}$ in a preparation chamber of the XPS unit was performed at $300{ }^{\circ} \mathrm{C}$ for $1 \mathrm{~h}$ [22]. After the pretreatment, the sample was transferred to an analytical chamber without contact with air.

Activity of the catalysts in the decomposition of FA ( 5 vol. \% $\mathrm{HCOOH} / \mathrm{He})$ was measured using a flow setup. A $20 \mathrm{mg}$ catalyst sample was uniformly mixed with $0.5 \mathrm{~cm}^{3}$ of quartz sand (grain size of $0.25-0.5 \mathrm{~mm}$ ). The reaction mixture preheated to $100{ }^{\circ} \mathrm{C}$ in a special box was fed into the reactor at a rate of $20 \mathrm{~cm}^{3} / \mathrm{min}$. The experiments were carried 
out in the temperature-programmed mode at a ramp rate of $2^{\circ} / \mathrm{min}$ with chromatographic analysis of the gas mixture. Before measuring the activity, the catalyst was reduced in a $10 \%$ $\mathrm{H}_{2} / \mathrm{He}$ mixture at $200{ }^{\circ} \mathrm{C}$ for $1 \mathrm{~h}$. The apparent turnover frequency (TOF) was calculated as a ratio of the reaction rate measured at low $(<20 \%)$ conversions to the total number of palladium atoms in the catalysts.

\section{Results}

\subsection{Properties of N-CNTs}

Nitrogen-doped carbon nanotubes were synthesized by the CVD method, which is widely applied to obtain N-CNTs [23-26]. As seen in Table 1, by increasing the ammonia concentration in the $\mathrm{C}_{2} \mathrm{H}_{4}-\mathrm{NH}_{3}$ reaction mixture $\left(25,40,60\right.$ and $75 \% \mathrm{NH}_{3}$ ), one can monotonically increase the degree of nitrogen doping of nanotubes from 1.8 to 6.6 at.\% with a simultaneous decrease in the yield of N-CNTs from 38 to $5 \mathrm{~g} \mathrm{C} / \mathrm{g}$ of catalyst. Such an effect of N/C ratio on the nitrogen content in N-CNTs was described by other authors for different reaction mixtures [24,26,27]. In turn, a decrease in the yield of N-CNTs is related to deactivation of the catalyst due to its encapsulation (Figure 1), which has been reported by many authors for the CVD synthesis of N-CNTs and other carbon materials [25,26,28-30].

Table 1. Properties of nitrogen-doped carbon nanotubes (N-CNTs): N/C and $\mathrm{N}_{\mathrm{Py}} / \mathrm{N}_{\mathrm{Q}}$ ratios according to XPS data, $\mathrm{I}_{\mathrm{D}} / \mathrm{I}_{\mathrm{G}}$ and $\mathrm{I}_{2 \mathrm{D}} / \mathrm{I}_{\mathrm{D}}$ ratios according to Raman spectroscopy, $\mathrm{S}_{\mathrm{BET}}$ values and product yield.

\begin{tabular}{ccccccc}
\hline $\begin{array}{c}\text { Sample-NH } \\
\text { Concentration (\%) }\end{array}$ & $\begin{array}{c}\mathbf{N} / \mathbf{C} \\
\text { at. } \%\end{array}$ & $\mathbf{N}_{\mathbf{P y}} / \mathbf{N}_{\mathbf{Q}}$ & $\mathbf{I}_{\mathbf{D}} / \mathbf{I}_{\mathbf{G}}$ & $\mathbf{I}_{\mathbf{2 D}} / \mathbf{I}_{\mathbf{D}}$ & $\left.\mathbf{S}_{\mathbf{B E T}}, \mathbf{( m}^{\mathbf{2}} / \mathbf{g}\right)$ & $\begin{array}{c}\text { Yield, } \\
\text { (g C/g of Catalyst) }\end{array}$ \\
\hline CNTs & - & - & 2.4 & 0.28 & 155 & 38 \\
N-CNTs-25 & 1.8 & 0.5 & 2.7 & 0.15 & 148 & 30 \\
N-CNTs-40 & 2.8 & 0.7 & 2.8 & 0.15 & 160 & 22 \\
N-CNTs-60 & 4.4 & 0.9 & 3.0 & 0.13 & 158 & 14 \\
N-CNTs-75 & 6.6 & 1.2 & 3.7 & 0.12 & 151 & 5 \\
\hline
\end{tabular}

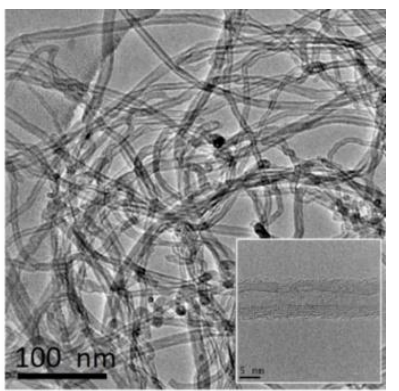

(a)

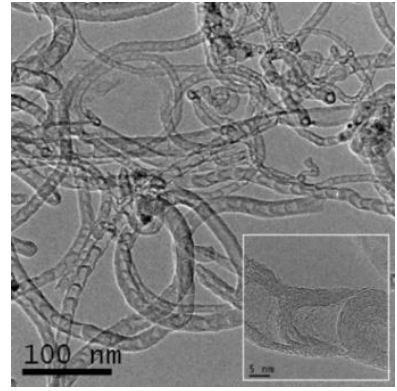

(b)

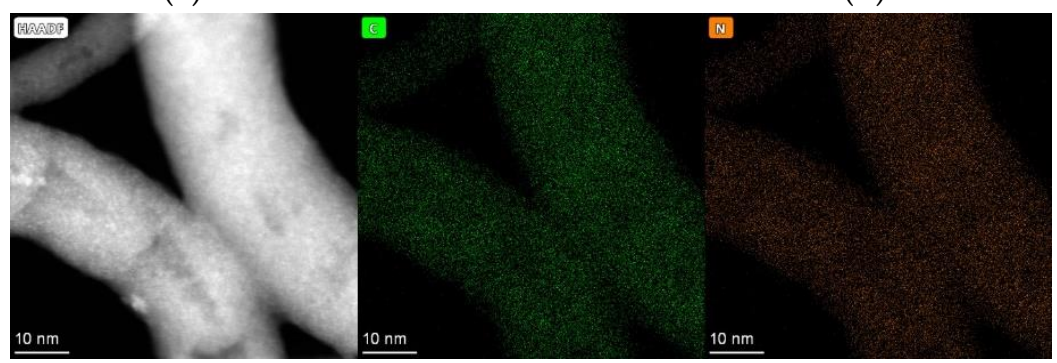

(c)

Figure 1. (a) TEM images of CNTs; (b) 4.4 at.\% N-CNTs; and (c) HAADF-STEM image, color overlay of the corresponding EDX maps of carbon and nitrogen presented in background-corrected intensities.

TEM micrographs of the 4.4 at.\% N-CNTs as an example and CNTs are displayed in Figure 1. Ethylene decomposition is accompanied by the predominant formation of multiwalled carbon nanotubes. In their turn, N-CNTs have a distinct bamboo-like structure, which is known to form due to the curvature of nitrogen-containing graphene layers [31,32]. 
According to STEM-HAADF images with elemental mapping, nitrogen is uniformly distributed in N-CNTs.

XPS revealed (Figure 2) that nitrogen in N-CNTs is in pyridinic $\left(\mathrm{N}_{\mathrm{Py}}, \sim 398 \mathrm{eV}\right)$, pyrrolic $\left(\mathrm{N}_{\mathrm{Pyr}}, \sim 400 \mathrm{eV}\right)$, graphitic $\left(\mathrm{N}_{\mathrm{Q}}, \sim 401 \mathrm{eV}\right)$, oxidized $\left(\mathrm{N}_{\mathrm{Ox}}, \sim 403 \mathrm{eV}\right)$ and molecular $\left(\mathrm{N}_{\mathrm{N} 2}\right.$, $\sim 405 \mathrm{eV}$ ) states $[24,26,33]$. The presence of molecular nitrogen encapsulated between graphene layers or inside channels is characteristic of bamboo-like N-CNTs [26,34]. An increase in the total nitrogen content in N-CNTs is accompanied by an increase in the content of all structural species. However, this changes the predominant species and the ratio of nitrogen species. In the N-CNTs with the minimum doping degree, the main contribution is made by graphitic nitrogen, and the $\mathrm{N}_{\mathrm{Py}} / \mathrm{N}_{\mathrm{Q}}$ ratio is equal to 0.5 , Table 1 . As the total nitrogen content is increased, the contribution of pyridinic nitrogen grows; as a result, the $\mathrm{N}_{\mathrm{Py}} / \mathrm{N}_{\mathrm{Q}}$ value achieves 1.2 in the case of 6.6 at.\% N-CNTs.
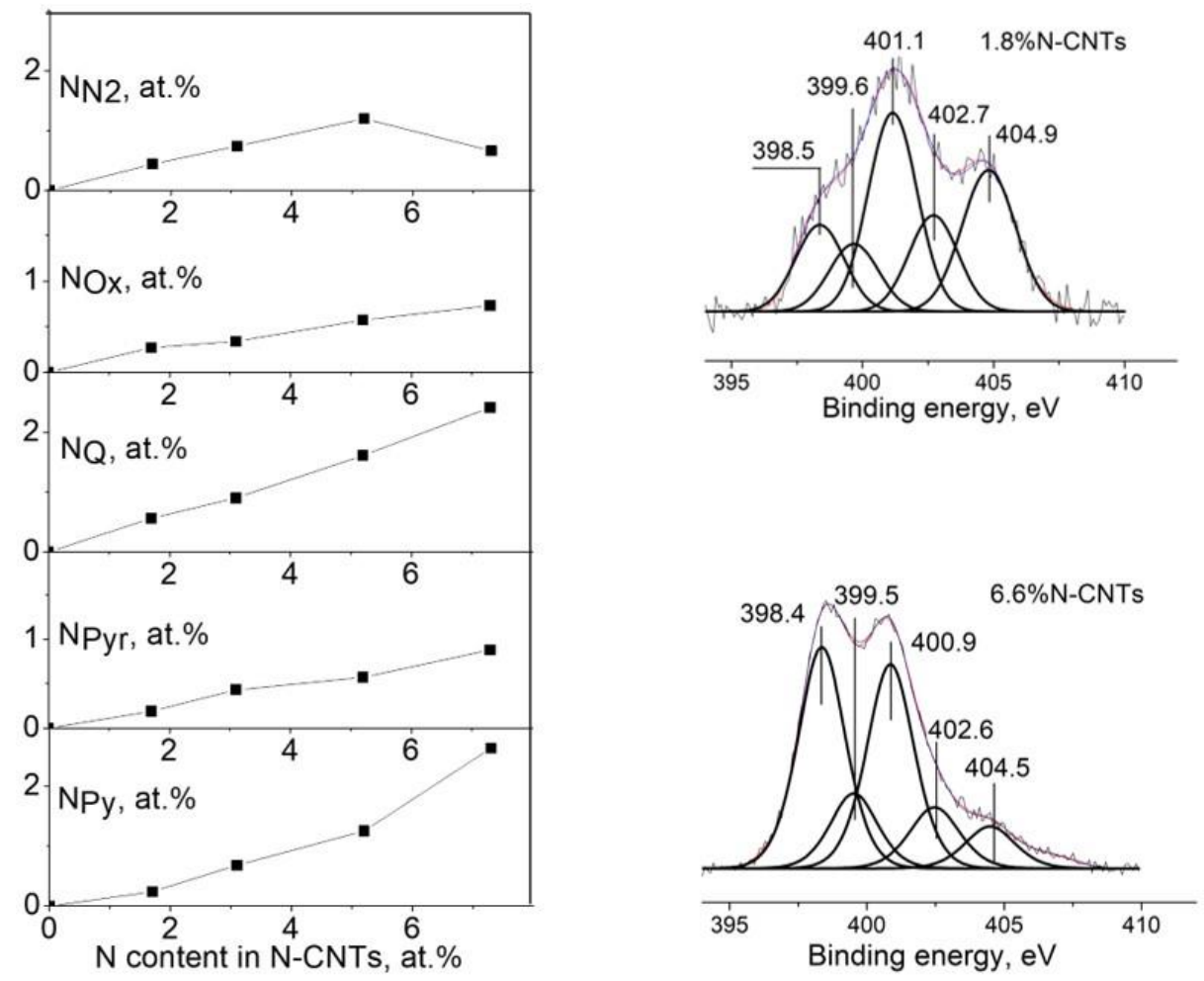

Figure 2. Input of different types of nitrogen in N-CNTs (left); N1s XPS spectra of $1.8 \%$ at.\% N-CNTs and $6.6 \%$ at. $\% \mathrm{~N}-\mathrm{CNTs}$ (right).

It is known that nitrogen incorporation in the pyridinic positions of graphene layers is accompanied by the formation of carbon vacancies, i.e., by an increase in structural defectivity. Indeed, the formation of such fragments was observed in TEM images of $\mathrm{N}$-CNTs obtained at atomic resolution [23]. The formation of such structural elements was confirmed by a growth of the $\mathrm{I}_{\mathrm{D}} / \mathrm{I}_{\mathrm{G}}$ ratio with a simultaneous decrease in the $\mathrm{I}_{2 \mathrm{D}} / \mathrm{I}_{\mathrm{D}}$ ratio revealed by Raman spectroscopy (Table 1 ). The $\mathrm{I}_{\mathrm{D}} / \mathrm{I}_{\mathrm{G}}$ ratio reflects defectivity of carbon nanomaterials $[35,36]$, while the $\mathrm{I}_{2 \mathrm{D}} / \mathrm{I}_{\mathrm{D}}$ ratio is used to analyze the size of the defect-free graphene blocks $[37,38]$ (Figure 3). In our earlier work, the XRD study of N-CNTs and their structural simulation gave grounds to suppose the formation of the fragments similar to the structural elements of the $\mathrm{g}-\mathrm{C}_{3} \mathrm{~N}_{4}$ layer comprising the ordered carbon vacancies and pyridinic nitrogen atoms [20]; the estimated size of such a fragment of the layer is not smaller than $5 \AA$. 


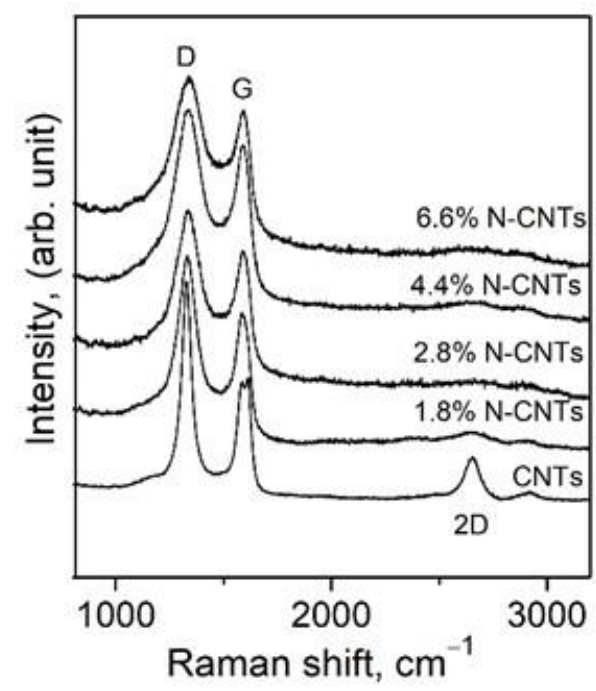

Figure 3. Raman spectra of CNTs and N-CNTs.

However, it should be noted that the obtained XPS data do not provide information on the surface state of N-CNTs with respect to different nitrogen species, which is an important factor when these materials are employed as the catalyst supports. In this context, N-CNTs were additionally studied by synchrotron-based XPS with variation of the analysis depth using radiation energies of 500 and $800 \mathrm{eV}$. The data obtained were compared with the results of standard XPS study performed at $1486.6 \mathrm{eV}$. The radiation energies of 500, 800 and $1486.6 \mathrm{eV}$ allowed us to acquire data at the analysis depths of ca. 1.6, ca. 3 and ca. $6 \mathrm{~nm}$, respectively (Figure 4). According to TEM data displayed in Figure 1b, the mean wall thickness of N-CNTs is ca. $5 \mathrm{~nm}$. Hence, when the depth of analysis is varied from 1.6 to $6 \mathrm{~nm}$, the acquired data could provide information on the nitrogen in external/internal graphene layers, and partially in internal arches.

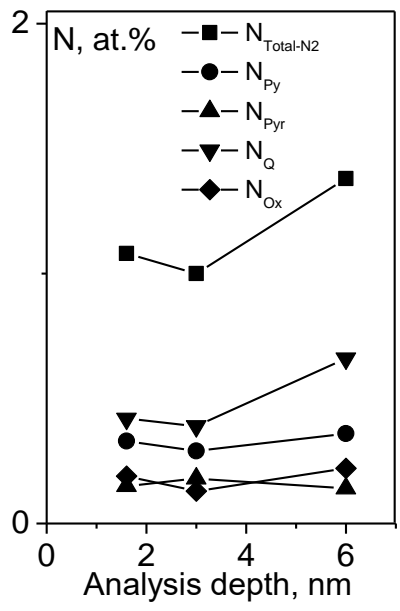

(a)

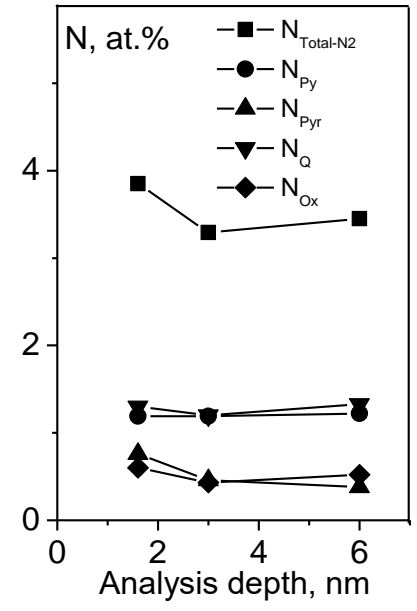

(b)

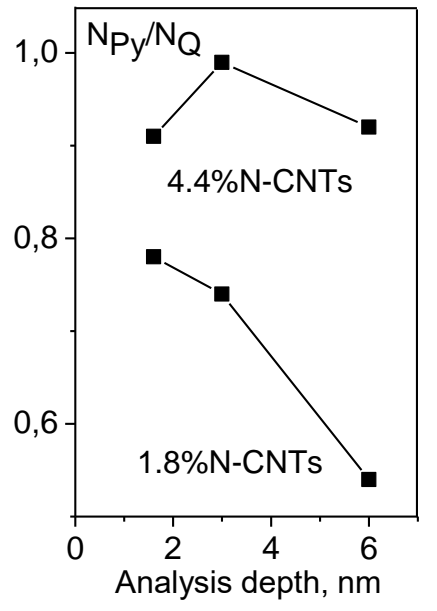

(c)

Figure 4. Content of nitrogen species in (a) 1.8\% at.\% N-CNTs and in (b) $4.4 \%$ at. $\%$ N-CNTs and (c) $\mathrm{N}_{\mathrm{Py}} / \mathrm{N}_{\mathrm{Q}}$ ratio in N-CNTs in dependence on the analysis depth

One can see that in both samples, nitrogen is incorporated in all structural positions of external/internal graphene layers and internal arches. The total nitrogen concentration profile along the analysis depth coincides to a greater extent with the profile of different nitrogen species, which is determined most likely by the catalytic growth mechanism of $\mathrm{N}$-CNTs on the Fe catalyst with the equiprobable incorporation of nitrogen in different positions [24]. As seen in Figure 4c, when the entire tube wall (ca. $6 \mathrm{~nm}$ ) or only its external/subsurface layers (ca. $1.5 \mathrm{~nm}$ ) are analyzed, $\mathrm{N}_{\mathrm{Py}} / \mathrm{N}_{\mathrm{Q}}$, ratios for 4.4 at. $\% \mathrm{~N}-\mathrm{CNTs}$ 
virtually do not differ. In the case of 1.8 at.\% N-CNTs, as the depth of analysis is decreased, the $\mathrm{N}_{\mathrm{Py}} / \mathrm{N}_{\mathrm{Q}}$ ratio increases by a factor of ca. 1.6. Nevertheless, our study of N-CNTs with the minimum depth of analysis allows a conclusion that external layers of N-CNTs, irrespective of the doping degree, are slightly enriched with graphitic nitrogen.

To choose a method of palladium deposition on N-CNTs, their textural and adsorption properties were investigated. As seen in Table 1, nitrogen doping of CNTs does not produce changes in the textural characteristics of carbon nanotubes. Indeed, their specific surface area changes in a narrow range of $148-160 \mathrm{~m}^{2} / \mathrm{g}$, and pore size distribution curves for all the samples are similar and have distinct maxima in the regions of 3-4 nm and 25-40 nm (Figure 5). Fenelonov et al. [39] proposed that pores with the size of 3-4 nm are formed due to the curvature of graphene layers, whereas larger pores emerge due to the entangled weave of N-CNTs leading to the formation of multiple voids.

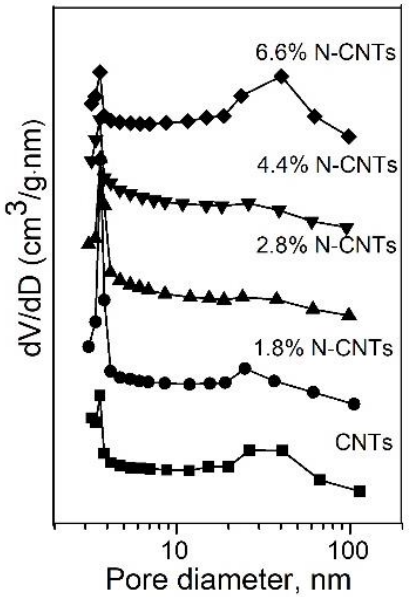

(a)

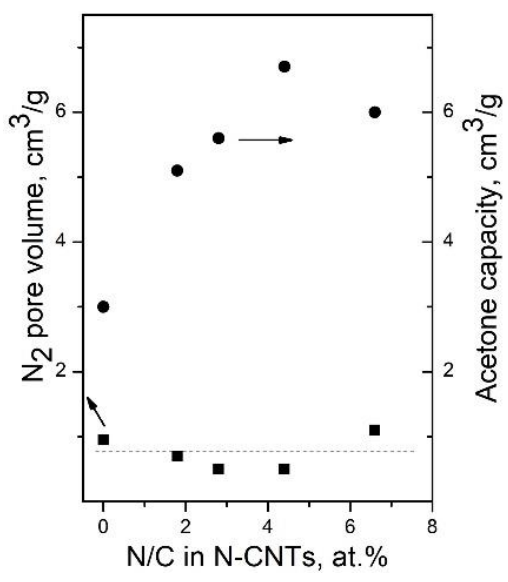

(b)

Figure 5. (a) Pore size distribution curves and (b) $\mathrm{N}_{2}$ pore volume and acetone capacity of the CNTs and N-CNTs.

However, an increase in the nitrogen content in N-CNTs is accompanied by a considerable growth of their capacity towards acetone, from 3 to $\sim 6-7 \mathrm{~cm}^{3} / \mathrm{g}$, which was used as a solvent in the deposition of palladium catalyst (Figure $5 b$ ). This suggests that such a high acetone capacity of N-CNTs is achieved due to the bulk filling of inner channels of the tubes in spite of multiple regular internal arches (Figure 1b). Note that the values of acetone capacity of fresh and treated in $2 \mathrm{M} \mathrm{HCl}$ carbons are the same. In turn, a good correlation between nitrogen content in N-CNTs and $\mathrm{N}_{P y} / \mathrm{N}_{\mathrm{Q}}, \mathrm{I}_{\mathrm{D}} / \mathrm{I}_{\mathrm{G}}$ and $\mathrm{I}_{2 \mathrm{D}} / \mathrm{D}$ ratios was found (Table 1). Therefore, it can be supposed that the presence of large defects (not smaller than $5 \AA$ ) in graphene layers of the synthesized N-CNTs, which are represented by the ordered carbon vacancies surrounded with pyridinic nitrogen atoms [20], improves their wettability and makes the capillary effect more pronounced. Kumar et al. [40] calculated isotherms of water adsorption on disordered $\mathrm{N}-\mathrm{C}$ materials and attributed the anomalously high adsorption to the implementation of a specific mechanism, according to which 1D, 2D and 3D nucleation, accompanied by the formation of solvent clusters which resembles the growth of crystals, was followed by bulk condensation. The filling of the inner channels of N-CNTs may indicate that during their deposition on N-CNTs by wet chemistry methods, metals can be anchored not only on the external surface but also in the inner channels of nanotubes [41]. On the other hand, Hao et al. [42] conclude that high hydrophilicity of $\mathrm{N}$-doped carbon nanomaterials ensures a high dispersion of supported metallic catalysts, thus increasing their activity.

\subsection{Properties of $\mathrm{Pd} / \mathrm{N}-\mathrm{CNTS}$ Catalysts}

A series of $\mathrm{Pd} / \mathrm{N}-\mathrm{CNT}$ catalysts $(0.2,0.5,1$ and 2 wt. $\%$ of $\mathrm{Pd})$ were synthesized using the N-CNTs that were obtained by decomposition of the $40 \% \mathrm{C}_{2} \mathrm{H}_{4}-60 \% \mathrm{NH}_{3}$ mixture. The 
choice of support was based on the optimal combination of the nitrogen content in carbon nanotubes and the yield of N-CNTs (Table 1). To study the interaction of palladium with the N-CNTs surface, the concentration of palladium was varied from 0.2 to $2 \mathrm{wt} . \%$. N-free catalysts $0.2 \% \mathrm{Pd} / \mathrm{CNTs}$ and $2 \% \mathrm{Pd} / \mathrm{CNTs}$ were synthesized for comparison purposes. The revealed high affinity of N-CNTs for acetone, which was used in our study as a solvent of palladium salt, explains the uniform distribution of palladium in the catalysts and the absence of agglomerates (Figure 6). In addition, as seen in Figure 6b, it cannot be ruled out that individual palladium particles are located in the inner channels of nanotubes. In the X-ray diffraction patterns, a weak intensity peak related to Pd 111 was recorded only for the catalysts with a maximum metal content ( $2 \mathrm{wt} . \%$; see Figure 7 ). The X-ray diffraction patterns of all other catalysts show only the maxima related to the carbon phase.

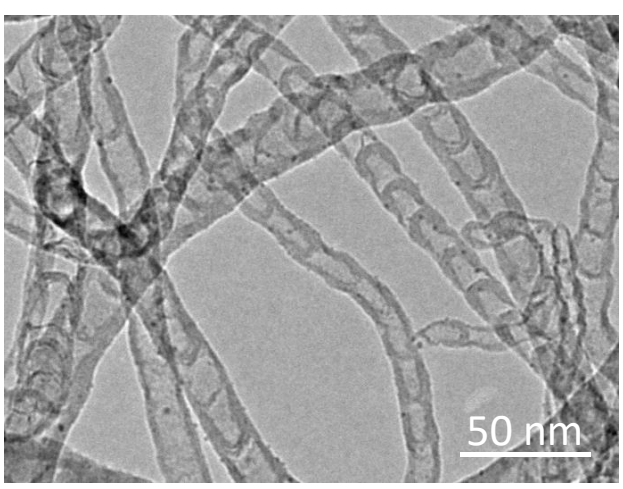

(a)

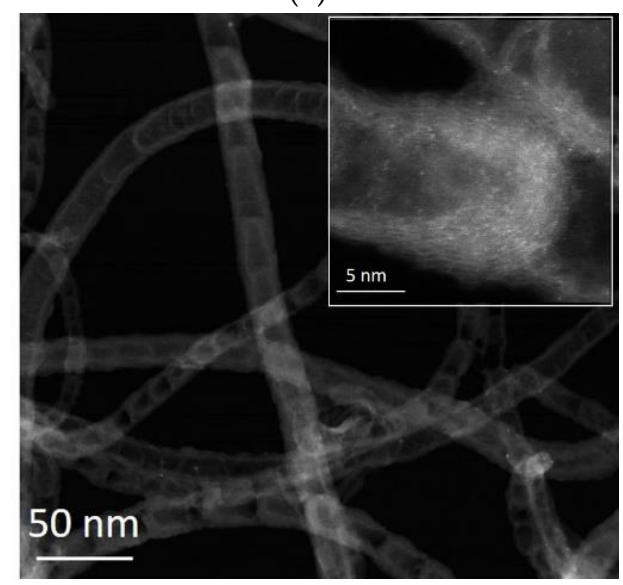

(c)

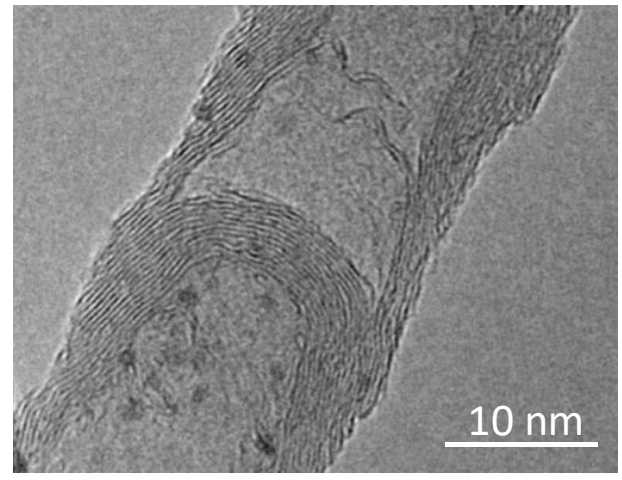

(b)

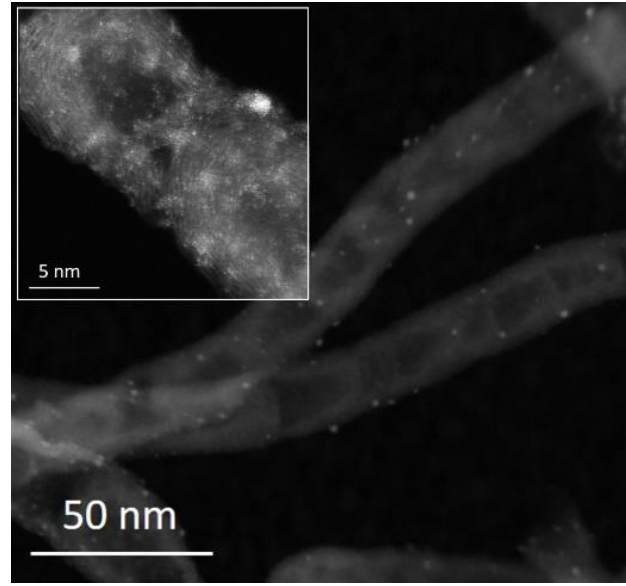

(d)

Figure 6. $(\mathbf{a}, \mathbf{b})$ TEM images of $2 \%$ Pd/N-CNTs; HAADF-STEM images of (c) $0.2 \%$ Pd/N-CNTs and (d) $2 \% \mathrm{Pd} / \mathrm{N}-\mathrm{CNTs}$

TOF values for FA decomposition on nitrogen-doped and nitrogen-free catalysts are shown in Table 2 and Figure 8. In the case of $\mathrm{N}$-free catalysts, a ten-fold increase in palladium content was accompanied by a decrease in apparent TOF from 180 to $72 \mathrm{~h}^{-1}$, with a simultaneous decrease in $\mathrm{CO} / \mathrm{Pd}$ ratio from 33.5 to $22.1 \%$, according to the $\mathrm{CO}$ chemisorption data. Indeed, the mean particle size for $0.2 \% \mathrm{Pd} / \mathrm{CNTs}$ was $1.2 \mathrm{~nm}$, whereas for $2 \% \mathrm{Pd} / \mathrm{CNTs}$ it was $2.3 \mathrm{~nm}$. According to the XPS, palladium was in the metallic state and the binding energy of $\mathrm{Pd} 3 \mathrm{~d}$ was $335.6 \mathrm{eV}$ (Figure 9). This value is typical of the dispersed metallic palladium particles [43,44]. The TOF values of the $0.2 \% \mathrm{Pd} / \mathrm{CNTs}$ and $2 \% \mathrm{Pd} / \mathrm{CNTs}$ catalysts calculated as a ratio of the reaction rate to the number of surface palladium atoms were 193 and $147 \mathrm{~h}^{-1}$, respectively. The observed difference in TOF values may be due to different palladium crystallinity or its different localization in the tubes (outer surface and inner channels). Selectivity of the catalysts towards hydrogen formation did not exceed $92 \%$. 


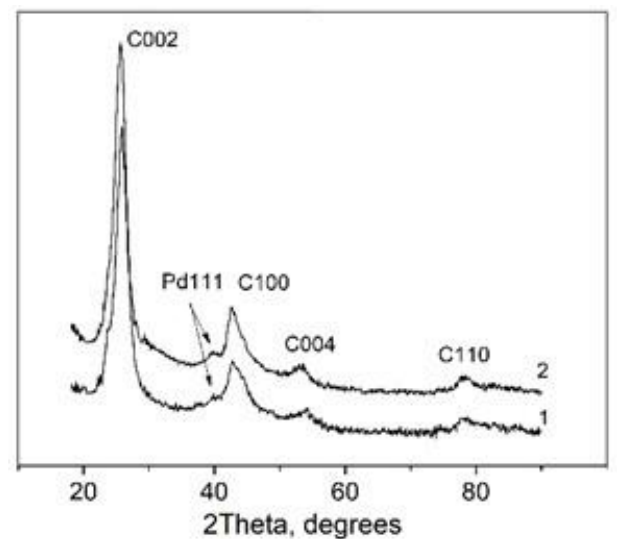

Figure 7. XRD patterns of $2 \% \mathrm{Pd} / \mathrm{N}-\mathrm{CNTs}(1)$ and $2 \% \mathrm{Pd} / \mathrm{CNTs}(2)$.

Table 2. Some characteristics of Pd supported catalysts: mean Pd size determined by TEM, TOF at $125^{\circ} \mathrm{C}$ and selectivity at $25 \%$ formic acid (FA) conversion.

\begin{tabular}{cccc}
\hline Catalyst & Pd Size $(\mathbf{n m})$ & TOF $\left(\mathbf{h}^{-\mathbf{1}}\right)$ & S (\%) \\
\hline $0.2 \%$ Pd $/ \mathrm{N}-\mathrm{CNTs}$ & not detectable & 324 & 97 \\
$0.5 \%$ Pd/N-CNTs & not detectable & 252 & 97 \\
$1 \% \mathrm{Pd} / \mathrm{N}-\mathrm{CNTs}$ & 1.3 & 297 & 98 \\
$2 \% \mathrm{Pd} / \mathrm{N}-\mathrm{CNTs}$ & 1.4 & 225 & 98 \\
$0.2 \% \mathrm{Pd} / \mathrm{CNTs}$ & 1.2 & 180 & 92 \\
$2 \% \mathrm{Pd} / \mathrm{CNTs}$ & 2.3 & 72 & 92 \\
\hline
\end{tabular}

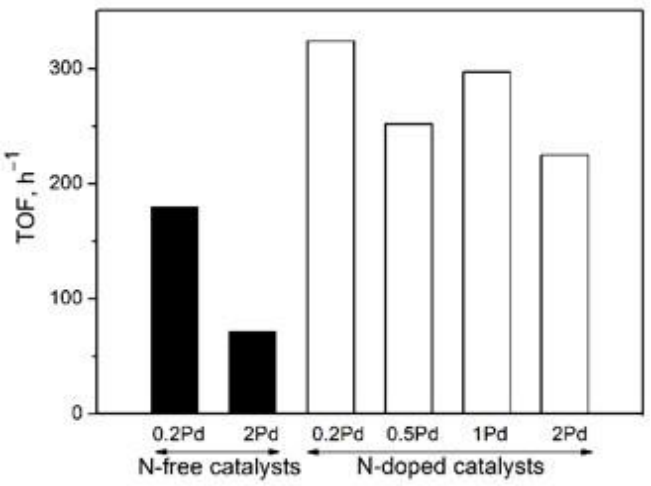

(a)

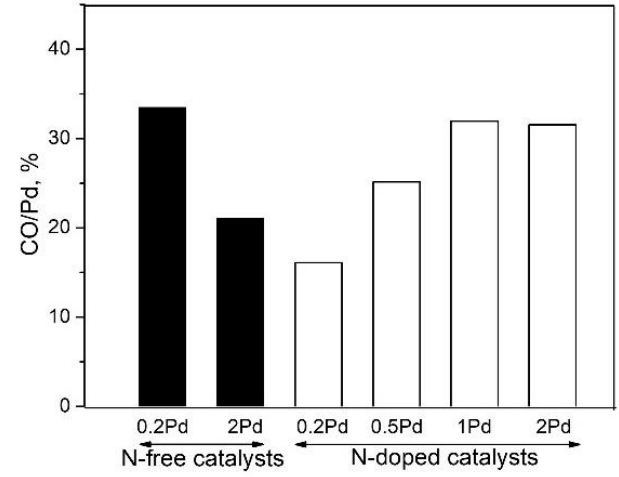

(b)

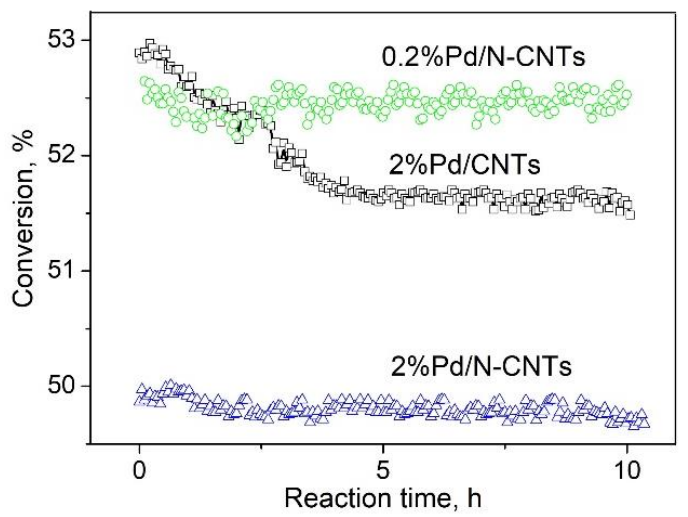

(c)

Figure 8. (a) TOF values for FA decomposition at $125^{\circ} \mathrm{C}$; (b) $\mathrm{CO} / \mathrm{Pd}$ ratio for nitrogen-free and nitrogen-doped catalysts with different Pd loading and stability test of the $0.2 \% \mathrm{Pd} / \mathrm{N}-\mathrm{CNTs}, 2 \% \mathrm{Pd} / \mathrm{N}-\mathrm{CNTs}$ and (c) $2 \% \mathrm{Pd} / \mathrm{CNTs}$ at $\sim 50 \%$ FA conversion in the course of the reaction. 

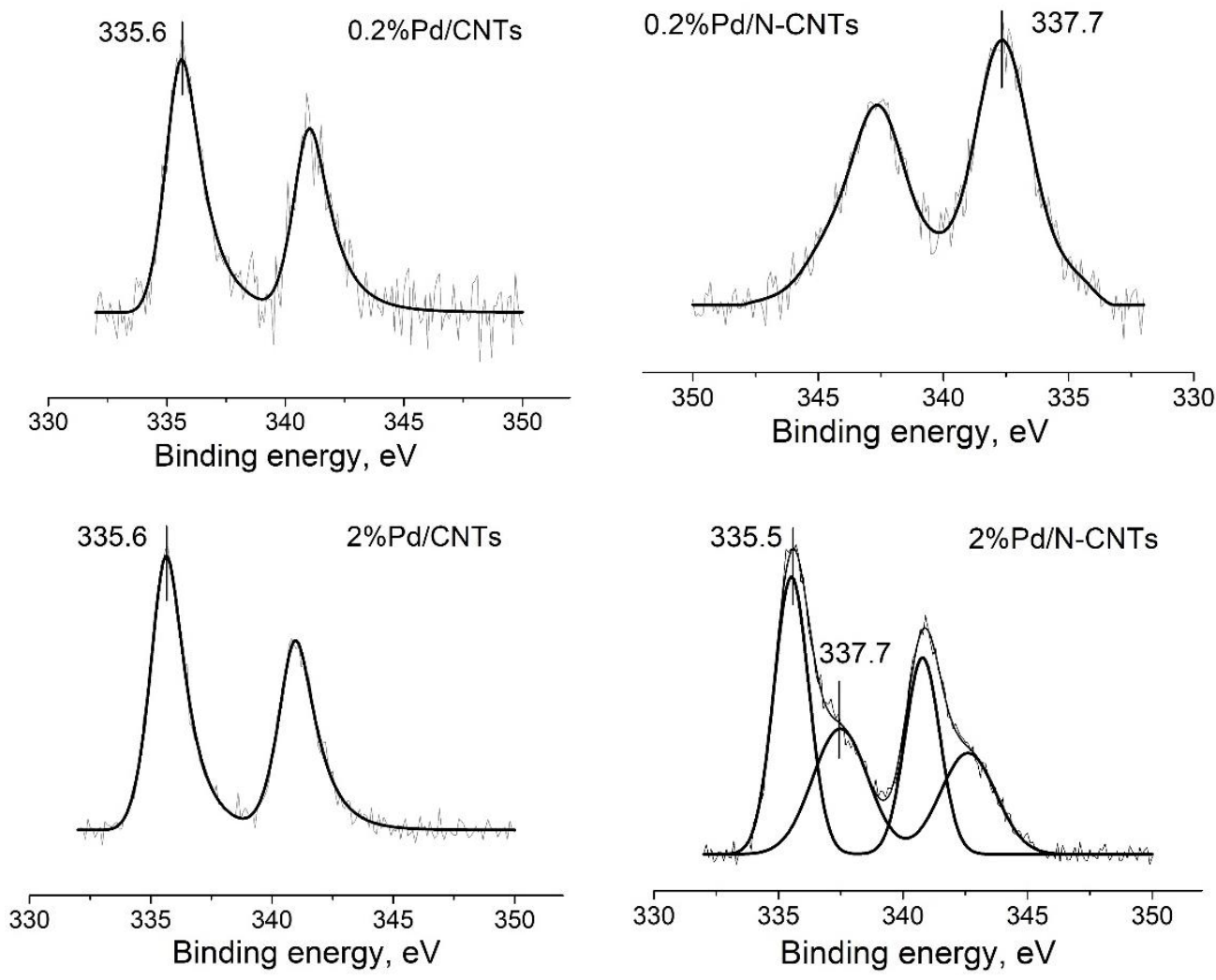

Figure 9. Pd 3d XPS spectra of nitrogen-free (0.2\% Pd/CNTs and $2 \% \mathrm{Pd} / \mathrm{CNTs})$ and nitrogen-doped $(0.2 \% \mathrm{Pd} / \mathrm{N}-\mathrm{CNTs}$ and $2 \% \mathrm{Pd} / \mathrm{N}-\mathrm{CNTs})$ catalysts.

All the nitrogen-doped catalysts, irrespective of palladium content, demonstrated the increased activity and selectivity (97-98\%) in comparison with $0.2-2 \% \mathrm{Pd} / \mathrm{CNTs}$ catalysts. TOF values varied in a narrow range of $225-324 \mathrm{~h}^{-1}$; the maximum activity was observed for the $0.2 \% \mathrm{Pd} / \mathrm{N}-\mathrm{CNT}$ catalyst. The dependence of $\mathrm{CO} / \mathrm{Pd}$ on palladium content for this series of catalysts had a complicated shape. A decrease in palladium content from 2 to $1 \%$ was not accompanied by changes in $\mathrm{CO} / \mathrm{Pd}$, and a further decrease in $\mathrm{Pd}$ concentration to $0.2 \%$ produced a sharp drop in $\mathrm{CO} / \mathrm{Pd}$ from 32 to $16.1 \%$. The observed dependence of $\mathrm{CO} / \mathrm{Pd}$ on palladium content did not correlate with the TEMdata, according to which mean particle size for the catalysts with $2 \% \mathrm{Pd}$ and $1 \% \mathrm{Pd}$ was equal to 1.4 and $1.3 \mathrm{~nm}$, respectively (Table 2), whereas for $0.5 \% \mathrm{Pd}$ and $0.2 \% \mathrm{Pd}$ it could not be determined owing to their small sizes. An HAADF-STEM study of $0.2 \% \mathrm{Pd} / \mathrm{N}-\mathrm{CNTs}$ showed that the catalyst consisted predominantly of isolated palladium atoms (Figure 6 ). The $2 \% \mathrm{Pd} / \mathrm{N}$ CNT catalyst contained not only nanoparticles but also a considerable amount of single palladium atoms. As seen in Figure 9, the binding energy of palladium in $0.2 \% \mathrm{Pd} / \mathrm{N}$ CNTs was $337.7 \mathrm{eV}$, which may correspond to both the PdO [45] and the ionic palladium stabilized on pyridinic centers of N-CNTs [46]. However, oxidation of the samples was completely excluded in XPS studies; therefore, Pd 3d BE $337.7 \mathrm{eV}$ can reliably be assigned to $\mathrm{Pd}^{2+}-\mathrm{N}_{\mathrm{Py}}$ species. Some studies have demonstrated that $\mathrm{Pd}^{2+}-\mathrm{N}_{\mathrm{Py}}$ species, in distinction to $\mathrm{Pd}^{0}$, weakly chemisorb CO $[12,46]$. In the case of $2 \% \mathrm{Pd} / \mathrm{N}-\mathrm{CNTs}$, palladium is in the highly dispersed $\mathrm{Pd}^{0}(\mathrm{BE} P d \mathrm{~d} 335.5 \mathrm{eV})$ and $\mathrm{Pd}^{2+}-\mathrm{N}_{\mathrm{Py}}(\mathrm{BE} \mathrm{Pd} 3 \mathrm{~d} 337.7 \mathrm{eV})$ states.

\section{Discussion}

$\mathrm{Pd} / \mathrm{N}-\mathrm{CNTs}$ catalysts have been synthesized and examined in the gas-phase decomposition of FA for hydrogen production. To describe the interaction of palladium with $\mathrm{N}$-CNTs, palladium concentration was varied from 0.2 to $2 \mathrm{wt} . \%$, and a comparison with $\mathrm{N}$-free catalysts was made. XPS experiments with variation of the analysis depth demonstrated that nitrogen on the external graphene surface of N-CNTs was in all structural states. 
Irrespective of the doping degree, the predominance of graphitic nitrogen was observed. However, according to XPS and HAADF-STEM studies of the $0.2 \% \mathrm{Pd} / \mathrm{N}-\mathrm{CNT}$ catalyst, palladium starts interacting with pyridinic nitrogen centers of N-CNTs to produce isolated ions. Indeed, theoretical calculations show that palladium preferentially interacts with the $\mathrm{N}_{\text {Py }}$ centers of N-CNTs instead of the $\mathrm{N}_{\mathrm{Q}}$ centers to form a positive +0.5 e charge [47]. The binding energy of $\mathrm{Pd} 3 \mathrm{~d}$ in $0.2 \% \mathrm{Pd} / \mathrm{N}-\mathrm{CNTs}$ is $337.7 \mathrm{eV}$, which coincides well with the $\mathrm{BE} \mathrm{Pd} 3 \mathrm{~d}$ values for Pd/N-CNTs catalysts reported in literature [47,48]. In these studies, DFT calculations were used to propose the models of palladium anchoring on both the single $\mathrm{N}_{\mathrm{Py}}$ center and $3 \mathrm{~N}_{\mathrm{Py}}-\mathrm{V}$ (where $\mathrm{V}$ is the vacancy). It seems interesting that close $\mathrm{BE}$ $\mathrm{Pd} 3 \mathrm{~d}$ values of 336.9-338.5 eV were also obtained in the case of palladium deposition on g- $\mathrm{C}_{3} \mathrm{~N}_{4}$ or $\mathrm{CN}$ material derived from a metal-organic framework [12,19]. It was supposed that stabilization of isolated palladium ions occurs with the participation of four nitrogen centers $\left(2 \mathrm{~N}_{\mathrm{Py}}\right.$ and $\left.2 \mathrm{~N}_{\mathrm{Pyr}}\right)$ [19] or $6 \mathrm{~N}_{\mathrm{Py}}$, which forms structural elements of the g- $\mathrm{C}_{3} \mathrm{~N}_{4}$ graphene layer [12]. It should be noted that in the $0.2 \% \mathrm{Pd} / \mathrm{N}-\mathrm{CNTs}$ catalyst, the $\mathrm{N}_{\mathrm{Py}} / \mathrm{Pd}$ ratio is 25 , which makes it possible to implement any of the proposed models, including $\mathrm{Pd}$ anchoring on fragments of the layer, which are similar to $\mathrm{g}-\mathrm{C}_{3} \mathrm{~N}_{4}$. The possibility of the formation of such fragments in graphene layers of N-CNTs was demonstrated in our earlier study [20].

As the content of supported palladium is increased, this most likely leads to the filling of accessible $\mathrm{N}_{\mathrm{Py}}$ centers; as a result, metallic nanoparticles start to form (Figure 10). This assumption is supported by the obtained dependence of $\mathrm{CO} / \mathrm{Pd}$ on palladium content in the catalysts. It reflects the occurrence of competitive processes: an increase in $\mathrm{CO}$ chemisorption owing to the growing dispersion of metallic nanoparticles, and a decrease in $\mathrm{CO}$ chemisorption due to formation of ionic palladium. It should be noted that the involvement of $\mathrm{N}_{\mathrm{Q}}$ centers in the stabilization of metallic nanoparticles, which are more dispersed than in $\mathrm{N}$-free catalysts, cannot be ruled out; their involvement was derived, for example, by Shi et al. [6] from a $0.2 \mathrm{eV}$ shift of the corresponding maximum in the N1s spectrum towards higher binding energies. We did not observe any changes in the N1s spectrum of Pd/N-CNTs catalysts in comparison with N-CNTs. However, a $0.1 \mathrm{eV}$ shift of $\mathrm{BE} \mathrm{Pd} 3 \mathrm{~d}$ for a more dispersed $2 \% \mathrm{Pd} / \mathrm{N}-\mathrm{CNTs}(1.4 \mathrm{~nm})$ towards lower binding energies in comparison with $2 \% \mathrm{Pd} / \mathrm{CNTs}(2.3 \mathrm{~nm})$ provides the basis to suppose such a possibility. As a result, the involvement of nitrogen centers in the stabilization of palladium decreases the TOF value only by a factor of 1.4 at a ten-fold increase in palladium concentration. For $\mathrm{N}$-free catalysts, the TOF value decreases by a factor of 2.5 .

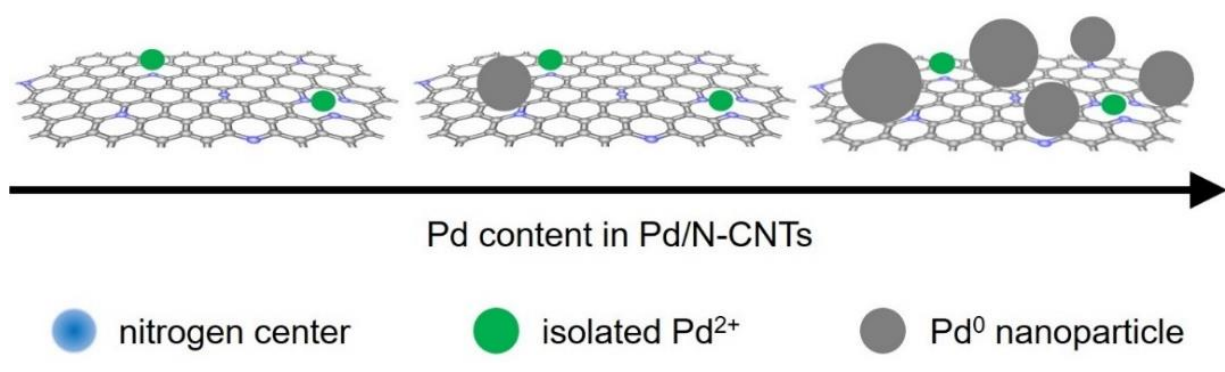

Figure 10. Schematic overview of the interaction of Pd with N-CNTs.

As shown by the catalytic experiments, isolated palladium ions are more active than metallic palladium nanoparticles, and the maximum TOF value is observed on the $0.2 \%$ $\mathrm{Pd} / \mathrm{N}-\mathrm{CNT}$ catalyst. A strong interaction of palladium with the pyridinic centers of $\mathrm{N}$-CNTs is responsible for high stability of the catalyst in the course of the reaction as compared to the N-free catalyst (Figure 8c). Presumably, activity of the catalysts with high palladium content is determined by the ratio of two palladium species and by the size of metallic nanoparticles. In comparison with $\mathrm{N}$-free catalysts, selectivity on all the $\mathrm{N}$-doped catalysts increased by $5 \%$, which corresponds to nearly a four-fold decrease in $\mathrm{CO}$ concentration. Additionally, the discovered stability of the catalyst $2 \% \mathrm{Pd} / \mathrm{N}-\mathrm{CNT}$ 
compared to $2 \% \mathrm{Pd} / \mathrm{CNT}$ confirms the stabilization of both palladium species (isolated ions and metal nanoparticles) by nitrogen centers [49].

\section{Conclusions}

Nitrogen centers of N-CNTs were shown to be efficient in the stabilization of different palladium species in the form of isolated ions and highly dispersed metal nanoparticles that are active towards formic acid decomposition for hydrogen production. This allows a conclusion that various nitrogen-containing carbon nanomaterials are promising for use as the supports of metallic catalysts for this reaction. Taking into account an increased activity of isolated palladium ions, it is more preferable to use N-CNMs with predominant pyridinic nitrogen centers in the external graphene layers.

Author Contributions: Conceptualization, O.Y.P.; data curation, A.N.S. and O.Y.P.; synthesis, A.N.S.; investigation, A.N.S. and O.Y.P.; methodology, O.Y.P.; writing-review and editing, O.Y.P. All authors have read and agreed to the published version of the manuscript.

Funding: This work was supported by the Russian Science Foundation (Grant No. 17-73-30032).

Institutional Review Board Statement: Not applicable.

Informed Consent Statement: Not applicable.

Data Availability Statement: Data is contained within the article.

Acknowledgments: The authors thank D. Svintsitskiy, A. Lisitsyn, O. Stonkus, V. Sobolev and A. Chuvilin for the performance of some physicochemical studies. The authors also thank D. Bulushev for discussion.

Conflicts of Interest: The authors declare no conflict of interest.

\section{References}

1. Grasemann, M.; Laurenczy, G. Formic acid as a hydrogen source-Recent developments and future trends. Energy Environ. Sci. 2012, 5, 8171-8181. [CrossRef]

2. Bulushev, D.A.; Ross, J.R.H. Towards Sustainable Production of Formic Acid. ChemSusChem 2018, 11, 821-836. [CrossRef] [PubMed]

3. Tang, Y.; Roberts, C.A.; Perkins, R.T.; Wachs, I.E. Revisiting formic acid decomposition on metallic powder catalysts: Exploding the HCOOH decomposition volcano curve. Surf. Sci. 2016, 650, 103-110. [CrossRef]

4. Tang, C.; Surkus, A.; Chen, F.; Pohl, M.; Agostini, G.; Schneider, M.; Junge, H.; Beller, M. A stable nanocobalt catalyst with highly dispersed CoNx active sites for the selective dehydrogenation of formic acid. Angew. Chem. 2017, 56, 16616-16620. [CrossRef] [PubMed]

5. He, L.; Weniger, F.; Neumann, H.; Beller, M. Synthesis, Characterization, and Application of Metal Nanoparticles Supported on Nitrogen-Doped Carbon: Catalysis beyond Electrochemistry. Angew. Chem. Int. Ed. 2016, 55, 12582-12594. [CrossRef]

6. Shi, W.; Zhang, B.; Lin, Y.; Wang, Q.; Zhang, Q.; Su, D.S. Enhanced Chemoselective Hydrogenation through Tuning the Interaction between Pt Nanoparticles and Carbon Supports: Insights from Identical Location Transmission Electron Microscopy and X-ray Photoelectron Spectroscopy. ACS Catal. 2016, 6, 7844-7854. [CrossRef]

7. Ning, X.; Yu, H.; Peng, F.; Wang, H. Pt nanoparticles interacting with graphitic nitrogen of N-doped carbon nanotubes: Effect of electronic properties on activity for aerobic oxidation of glycerol and electro-oxidation of CO. J. Catal. 2015, 325, 136-144. [CrossRef]

8. Ombaka, L.M.; Ndungu, P.G.; Nyamori, V.O. Pyrrolic nitrogen-doped carbon nanotubes: Physicochemical properties, interactions with Pd and their role in the selective hydrogenation of nitrobenzophenone. RSC Adv. 2015, 5, 109-122. [CrossRef]

9. Perini, L.; Durante, C.; Favaro, M.; Perazzolo, V.; Agnoli, S.; Schneider, O.; Granozzi, G.; Gennaro, A. Metal-Support Interaction in Platinum and Palladium Nanoparticles Loaded on Nitrogen-Doped Mesoporous Carbon for Oxygen Reduction Reaction. ACS Appl. Mater. Interfaces 2015, 7, 1170-1179. [CrossRef]

10. Liu, W.; Chen, Y.; Qi, H.; Zhang, L.; Yan, W.; Liu, X.; Yang, X.; Miao, S.; Wang, W.; Liu, C.; et al. A Durable Nickel Single-Atom Catalyst for Hydrogenation Reactions and Cellulose Valorization under Harsh Conditions. Angew. Chem. 2018, 57, 7071-7075. [CrossRef]

11. Huang, X.; Xia, Y.; Cao, Y.; Zheng, X.; Pan, H.; Zhu, J.; Ma, C.; Wang, H.; Li, J.; You, R.; et al. Enhancing both selectivity and coking-resistance of a single-atom Pd1/C3N4 catalyst for acetylene hydrogenation. Nano Res. 2017, 10, 1302-1312. [CrossRef]

12. Vilé, G.; Albani, D.; Nachtegaal, M.; Chen, Z.; Dontsova, D.; Antonietti, M.; López, N.; Pérez-Ramírez, J. A Stable Single-Site Palladium Catalyst for Hydrogenations. Angew. Chem. 2015, 54, 11265-11269. [CrossRef] [PubMed] 
13. Bulushev, D.A.; Zacharska, M.; Lisitsyn, A.S.; Podyacheva, O.Y.; Hage, F.S.; Ramasse, Q.M.; Bangert, U.; Bulusheva, L.G. Single Atoms of Pt-Group Metals Stabilized by N-Doped Carbon Nanofibers for Efficient Hydrogen Production from Formic Acid. ACS Catal. 2016, 6, 3442-3451. [CrossRef]

14. Golub, F.S.; Beloshapkin, S.; Gusel'Nikov, A.V.; Bolotov, V.A.; Parmon, V.N.; Bulushev, D.A. Boosting Hydrogen Production from Formic Acid over Pd Catalysts by Deposition of N-Containing Precursors on the Carbon Support. Energies 2019, 12, 3885. [CrossRef]

15. Nishchakova, A.D.; Bulushev, D.A.; Stonkus, O.A.; Asanov, I.P.; Ishchenko, A.V.; Okotrub, A.V.; Bulusheva, L.G. Effects of the Carbon Support Doping with Nitrogen for the Hydrogen Production from Formic Acid over Ni Catalysts. Energies 2019, $12,4111$. [CrossRef]

16. Podyacheva, O.; Lisitsyn, A.; Kibis, L.; Boronin, A.; Stonkus, O.; Zaikovskii, V.; Suboch, A.; Sobolev, V.; Parmon, V. Nitrogen Doped Carbon Nanotubes and Nanofibers for Green Hydrogen Production: Similarities in the Nature of Nitrogen Species, Metal-Nitrogen Interaction, and Catalytic Properties. Energies 2019, 12, 3976. [CrossRef]

17. Navlani-García, M.; Mori, K.; Salinas-Torres, D.; Kuwahara, Y.; Yamashita, H. New Approaches Toward the Hydrogen Production From Formic Acid Dehydrogenation Over Pd-Based Heterogeneous Catalysts. Front. Mater. 2019, 6, 44. [CrossRef]

18. Bulushev, D.A.; Bulusheva, L.G. Catalysts with single metal atoms for the hydrogen production from formic acid. Catal. Rev. 2021, 1-40. [CrossRef]

19. Wei, S.; Li, A.; Liu, J.-C.; Li, Z.; Chen, W.; Gong, Y.; Zhang, Q.; Cheong, W.-C.; Wang, Y.; Zheng, L.; et al. Direct observation of noble metal nanoparticles transforming to thermally stable single atoms. Nat. Nanotechnol. 2018, 13, 856-861. [CrossRef]

20. Podyacheva, O.Y.; Cherepanova, S.V.; Romanenko, A.I.; Kibis, L.S.; Svintsitskiy, D.A.; Boronin, A.I.; Stonkus, O.A.; Suboch, A.N.; Puzynin, A.V.; Ismagilov, Z.R. Nitrogen doped carbon nanotubes and nanofibers: Composition, structure, electrical conductivity and capacity properties. Carbon 2017, 122, 475-483. [CrossRef]

21. Svintsitskiy, D.A.; Kibis, L.S.; Smirnov, D.A.; Suboch, A.N.; Stonkus, O.A.; Podyacheva, O.Y.; Boronin, A.I.; Ismagilov, Z.R. Spectroscopic study of nitrogen distribution in $\mathrm{N}$-doped carbon nanotubes and nanofibers synthesized by catalytic ethyleneammonia decomposition. Appl. Surf. Sci. 2018, 435, 1273-1284. [CrossRef]

22. Podyacheva, O.Y.; Bulushev, D.A.; Suboch, A.N.; Svintsitskiy, D.A.; Lisitsyn, A.S.; Modin, E.; Chuvilin, A.; Gerasimov, E.Y.; Sobolev, V.I.; Parmon, V.N. Highly Stable Single-Atom Catalyst with Ionic Pd Active Sites Supported on N-Doped Carbon Nanotubes for Formic Acid Decomposition. ChemSusChem 2018, 11, 3724-3727. [CrossRef] [PubMed]

23. Terrones, M.; Ajayan, P.; Banhart, F.; Blase, X.; Carroll, D.; Charlier, J.-C.; Czerw, R.; Foley, B.; Grobert, N.; Kamalakaran, R.; et al. N-doping and coalescence of carbon nanotubes: Synthesis and electronic properties. Appl. Phys. A 2002, 74, 355-361. [CrossRef]

24. Chizari, K.; Janowska, I.; Houllé, M.; Florea, I.; Ersen, O.; Romero, T.; Bernhardt, P.; LeDoux, M.J.; Pham-Huu, C. Tuning of nitrogen-doped carbon nanotubes as catalyst support for liquid-phase reaction. Appl. Catal. A Gen. 2010, 380, 72-80. [CrossRef]

25. Van Dommele, S.; Romero-Izquirdo, A.; Brydson, R.; De Jong, K.; Bitter, J. Tuning nitrogen functionalities in catalytically grown nitrogen-containing carbon nanotubes. Carbon 2008, 46, 138-148. [CrossRef]

26. Bulusheva, L.G.; Okotrub, A.V.; Fedoseeva, Y.V.; Kurenya, A.G.; Asanov, I.P.; Vilkov, O.Y.; Koós, A.A.; Grobert, N. Controlling pyridinic, pyrrolic, graphitic, and molecular nitrogen in multi-wall carbon nanotubes using precursors with different $\mathrm{N} / \mathrm{C}$ ratios in aerosol assisted chemical vapor deposition. Phys. Chem. Chem. Phys. 2015, 17, 23741-23747. [CrossRef] [PubMed]

27. Tao, X.; Zhang, X.; Sun, F.; Cheng, J.; Liu, F.; Luo, Z. Large-scale CVD synthesis of nitrogen-doped multi-walled carbon nanotubes with controllable nitrogen content on a CoxMg1-xMoO4 catalyst. Diam. Relat. Mater. 2007, 16, 425-430. [CrossRef]

28. Kiciński, W.; Dyjak, S. Transition metal impurities in carbon-based materials: Pitfalls, artifacts and deleterious effects. Carbon 2020, 168, 748-845. [CrossRef]

29. Gulino, G.; Vieira, R.; Amadou, J.; Nguyen, P.; LeDoux, M.J.; Galvagno, S.; Centi, G.; Pham-Huu, C. C2H6 as an active carbon source for a large scale synthesis of carbon nanotubes by chemical vapour deposition. Appl. Catal. A Gen. 2005, 279 , 89-97. [CrossRef]

30. Guellati, O.; Begin, D.; Antoni, F.; Moldovan, S.; Guerioune, M.; Pham-Huu, C.; Janowska, I. CNTs' array growth using the floating catalyst-CVD method over different substrates and varying hydrogen supply. Mater. Sci. Eng. B 2018, $231,11-17$. [CrossRef]

31. Terrones, M.; Benito, A.; Manteca-Diego, C.; Hsu, W.; Osman, O.; Hare, J.; Reid, D.; Cheetham, A.; Prassides, K.; Kroto, H.; et al. Pyrolytically grown BxCyNz nanomaterials: Nanofibres and nanotubes. Chem. Phys. Lett. 1996, 257, 576-582. [CrossRef]

32. Han, W.-Q.; Kohler-Redlich, P.; Seeger, T.; Ernst, F.; Ruhle, M.; Grobert, N.; Hsu, W.-K.; Chang, B.-H.; Zhu, Y.-Q.; Kroto, H.W.; et al. Aligned $\mathrm{CN}(\mathrm{sub} \mathrm{x})$ nanotubes by pyrolysis of ferrocene/C(sub 60) under NH(sub 3) atmosphere. Appl. Phys. Lett. 2000, 77, 1807-1809. [CrossRef]

33. Lobiak, E.V.; Kuznetsova, V.R.; Makarova, A.A.; Okotrub, A.V.; Bulusheva, L.G. Structure, functional composition and electrochemical properties of nitrogen-doped multi-walled carbon nanotubes synthesized using Co-Mo, Ni-Mo and Fe-Mo catalysts. Mater. Chem. Phys. 2020, 255, 123563. [CrossRef]

34. Choi, H.C.; Park, J.; Kim, B. Distribution and Structure of N Atoms in Multiwalled Carbon Nanotubes Using Variable-Energy X-Ray Photoelectron Spectroscopy. J. Phys. Chem. B 2005, 109, 4333-4340. [CrossRef]

35. Dresselhaus, M.; Dresselhaus, G.; Saito, R.; Jorio, A. Raman spectroscopy of carbon nanotubes. Phys. Rep. 2005, 409, 47-99. [CrossRef] 
36. Dresselhaus, M.S.; Jorio, A.; Filho, A.G.S.; Saito, R. Defect characterization in graphene and carbon nanotubes using Raman spectroscopy. Philos. Trans. R. Soc. A Math. Phys. Eng. Sci. 2010, 368, 5355-5377. [CrossRef] [PubMed]

37. Podila, R.; Chacón-Torres, J.; Spear, J.T.; Pichler, T.; Ayala, P.; Rao, A.M. Spectroscopic investigation of nitrogen doped graphene. Appl. Phys. Lett. 2012, 101, 123108. [CrossRef]

38. Golubtsov, G.V.; Kazakova, M.A.; Selyutin, A.G.; Ishchenko, A.V.; Kuznetsov, V.L. Mono-, Bi-, and Trimetallic Catalysts for the Synthesis of Multiwalled Carbon Nanotubes Based on Iron Subgroup Metals. J. Struct. Chem. 2020, 61, 640-651. [CrossRef]

39. Fenelonov, V.; Derevyankin, A.; Okkel, L.; Avdeeva, L.; Zaikovskii, V.; Moroz, E.; Salanov, A.; Rudina, N.; Likholobov, V.; Shaikhutdinov, S. Structure and texture of filamentous carbons produced by methane decomposition on NI and NI-CU catalysts. Carbon 1997, 35, 1129-1140. [CrossRef]

40. Kumar, K.V.; Preuss, K.; Guo, Z.X.; Titirici, M.M. Understanding the Hydrophilicity and Water Adsorption Behavior of Nanoporous Nitrogen-Doped Carbons. J. Phys. Chem. C 2016, 120, 18167-18179. [CrossRef]

41. Chernyak, S.; Burtsev, A.; Maksimov, S.; Kupreenko, S.; Maslakov, K.; Savilov, S. Structural evolution, stability, deactivation and regeneration of Fischer-Tropsch cobalt-based catalysts supported on carbon nanotubes. Appl. Catal. A Gen. 2020, 603, 117741. [CrossRef]

42. Hao, G.-P.; Sahraie, N.R.; Zhang, Q.; Krause, S.; Oschatz, M.; Bachmatiuk, A.; Strasser, P.; Kaskel, S. Hydrophilic non-precious metal nitrogen-doped carbon electrocatalysts for enhanced efficiency in oxygen reduction reaction. Chem. Commun. 2015, 51, 17285-17288. [CrossRef]

43. Bueres, R.F.; Asedegbega-Nieto, E.; Díaz, E.; Ordóñez, S.; Diez, F.V. Performance of carbon nanofibres, high surface area graphites, and activated carbons as supports of Pd-based hydrodechlorination catalysts. Catal. Today 2010, 150, 16-21. [CrossRef]

44. Lesiak, B.; Mazurkiewicz, M.; Malolepszy, A.; Stobinski, L.; Mierzwa, B.; Mikolajczuk-Zychora, A.; Juchniewicz, K.; Borodzinski, A.; Zemek, J.; Jiricek, P. Effect of the Pd/MWCNTs anode catalysts preparation methods on their morphology and activity in a direct formic acid fuel cell. Appl. Surf. Sci. 2016, 387, 929-937. [CrossRef]

45. Fleisch, T.; Zajac, G.; Schreiner, J.; Mains, G. An XPS study of the UV photoreduction of transition and noble metal oxides. Appl. Surf. Sci. 1986, 26, 488-497. [CrossRef]

46. Arrigo, R.; Schuster, M.E.; Xie, Z.; Yi, Y.; Wowsnick, G.; Sun, L.L.; Hermann, K.E.; Friedrich, M.; Kast, P.; Hävecker, M.; et al. Nature of the N-Pd Interaction in Nitrogen-Doped Carbon Nanotube Catalysts. ACS Catal. 2015, 5, 2740-2753. [CrossRef]

47. He, Z.; Dong, B.; Wang, W.; Yang, G.; Cao, Y.; Wang, H.; Yang, Y.; Wang, Q.; Peng, F.; Yu, H. Elucidating Interaction between Palladium and N-Doped Carbon Nanotubes: Effect of Electronic Property on Activity for Nitrobenzene Hydrogenation. ACS Catal. 2019, 9, 2893-2901. [CrossRef]

48. Arrigo, R.; Wrabetz, S.; Schuster, M.E.; Wang, D.; Villa, A.; Rosenthal, D.; Girsgdies, F.; Weinberg, G.; Prati, L.; Schlögl, R.; et al. Tailoring the morphology of Pd nanoparticles on CNTs by nitrogen and oxygen functionalization. Phys. Chem. Chem. Phys. 2012, 14, 10523. [CrossRef] [PubMed]

49. Cao, Y.; Mao, S.; Li, M.; Chen, Y.; Wang, Y. Metal/Porous Carbon Composites for Heterogeneous Catalysis: Old Catalysts with Improved Performance Promoted by N-Doping. ACS Catal. 2017, 7, 8090-8112. [CrossRef] 